\title{
PAPER
}

\section{Prognostic value of platelet derived growth factor $\alpha$ receptor expression in grade 2 astrocytomas and oligoastrocytomas}

\author{
D Ribom*, J Andræ*, M Frielingsdorf, M Hartman, M Nistér, A Smits
}

J Neurol Neurosurg Psychiatry 2002;72:782-787

See end of article for authors' affiliations

Correspondence to:

Dr D Ribom, Department of

Neuroscience, Neurology,

University Hospital, SE-751

85, Uppsala, Sweden;

dan.ribom@neurologi.uu.se.

Received 11 June 2001

In revised form

24 October 2001

Accepted

15 January 2002

\begin{abstract}
Objective: To determine whether the expression of platelet derived growth factor $\alpha$ receptor (PDGFR $\alpha$ ) in low grade astrocytomas and oligoastrocytomas is associated with survival.

Methods: Formalin fixed and paraffin embedded tumour samples of 40 consecutive patients with supratentorial diffuse astrocytomas and oligoastrocytomas of WHO grade 2, resected between 1986 and 1993, were used for immunohistochemical staining. The fraction of tumour cells expressing PDGFR $\alpha$ protein was quantified and entered into univariate and multivariate survival analyses. Changes in PDGF $\alpha$ expression over time were analysed in seven patients in whom reoperations had been performed.

Results: Patients with a relatively high fraction of PDGFR $\alpha$ expressing cells had a more favourable outcome in both univariate $(p=0.04)$ and multivariate analyses $(p=0.02)$. Expression of PDGFR $\alpha$ was greater in oligoastrocytomas than in astrocytomas $(p=0.05)$. In four reoperated patients with histologically confirmed malignant transformation, there was a marked decrease in the number of cells expressing the receptor.

Conclusions: There is an association between high PDGFR $\alpha$ expression and long survival time in patients with grade 2 astrocytomas and oligoastrocytomas. The findings suggest that expression of the receptor may be a useful prognostic marker in such patients.
\end{abstract}

$\mathrm{P}$ atients with astrocytomas and oligoastrocytomas of World Health Organisation (WHO) grade 2 have a variable outcome and there is no consensus over the best treatment for such tumours. ${ }^{1}$ The extent and timing of surgery remain controversial in the absence of controlled trials. ${ }^{12}$ Prospective studies by the European Organisation for Research and Treatment of Cancer (EORTC) ${ }^{3-5}$ and the North Central Cancer Treatment Group (NCCTG) ${ }^{6}$ have not so far shown any convincing advantage of immediate high dose radiotherapy for patient survival in comparison with low dose or delayed radiotherapy.

Over the past decade there have been several attempts to identify biological markers that reflect the degree of tumour malignancy. Such markers might assist in the clinical management of patients with low grade gliomas by identifying those with a poor prognosis. Different methods have been used to estimate proliferative activity but there have been reports of limited reproducibility and high interobserver differences. ${ }^{17}$ It has been suggested that vascular endothelial growth factor (VEGF) expression and vascular density may be prognostic markers in grade 2 fibrillary astrocytomas. ${ }^{8}$

Platelet derived growth factor (PDGF), a potent mitogen for connective tissue and glial cells, is involved in pathological disorders such as inflammation, atherosclerosis, and cancer. ${ }^{9}$ The PDGF family consists of at least four gene productsPDGF-A, PDGF-B, PDGF-C, and PDGF-D-which selectively signal through two PDGF receptors $(\alpha$ and $\beta$ ) to regulate diverse cellular functions. ${ }^{10-13}$ Growth stimulation by PDGF is associated with the pathway of secondary glioblastomas, and the overexpression of the PDGF $\alpha$ receptor (PDGFR $\alpha$ ) is considered to be an early event in the progression of low grade gliomas. ${ }^{14}$ Several investigators have explored the role of PDGF and its receptors in the development of glial tumours, ${ }^{15}$ but no data are available on the correlation with survival. Our aim in the current study was to quantify the expression of PDGFR $\alpha$ in a group of patients with newly diagnosed grade 2 astrocy- tomas and oligoastrocytomas, and to investigate the prognostic significance of the degree of receptor expression.

\section{METHODS}

\section{Patients and tumour samples}

We undertook a retrospective review of two databases at the university hospital in Uppsala to identify patients with histologically verified supratentorial low grade gliomas with an astrocytic phenotype for the time period 1986 to 1993. Pilocytic astrocytomas, gangliogliomas, pleomorphic xanthoastrocytomas, dysembryoplastic neuroepithelial tumours, tumours with ependymal foci, oligodendrogliomas, and patients younger than 18 years at the time of diagnosis were excluded.

A semiquantitative assessment of the oligodendrocyte involvement was made and three categories were used: $<20 \%$, 20-40\%, and 40-60\%. Tumours containing 40-60\% oligodendrocytes were classified as oligoastrocytomas. The astrocytomas were further subclassified into fibrillary, gemistocytic, and protoplasmic variants.

After histological re-evaluation, the formalin fixed and paraffin embedded tumour materials from 43 patients with grade 2 astrocytomas and oligoastrocytomas according to the WHO classification $^{16}$ were identified for immunohistochemical staining of PDGFR $\alpha$. Three patients were excluded from analysis: one was lost to follow up (moved abroad), and in two cases the quality of the material was insufficient for further analysis. In seven patients, two pieces of tumour material were available, taken on different occasions.

\footnotetext{
*These authors contributed equally to this work.
} 

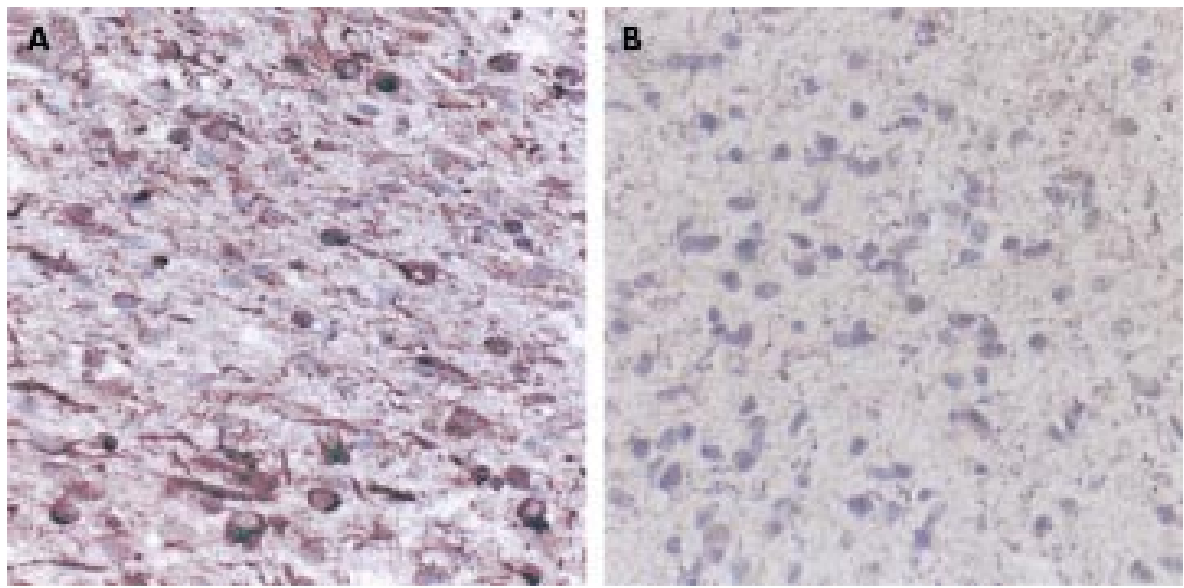

Figure 1 Immunohistochemical staining of a low grade astrocytoma with polyclonal antiserum against platelet derived growth factor $\alpha$ receptor (C-20), showing several positive tumour cells (A) and no immunoreactivity by omission of the antiserum (B).

\section{Clinical information}

The following information was collected by reviewing patient records and was used for the statistical analyses: age, sex, presenting symptoms, preoperative duration of symptoms, radiological appearance (tumour location and presence of contrast enhancement on computed tomography (CT) or magnetic resonance imaging (MRI)), preoperative and postoperative performance status according to the Karnofsky performance status scale, ${ }^{17}$ the type and extent of surgery (biopsy, subtotal resection, or total resection), histology, and radiotherapy (type and dose).

Reliable data on tumour size were only available in 25 cases, and the original CT and MRI scans had been destroyed. This variable was therefore not used in the analyses. The extent of surgical resection was based on the surgeons' operative notes or, when available, postoperative CT or MRI. Survival was defined as the time between the surgical procedure and the date of death or end of the study (4 August 2000). Progression-free survival was not used as a second end point because the patients were followed in different parts of our region with quite diverse methods of follow up, and this would have led to unacceptable bias. Data on the time and the cause of death were collected from central health authorities (the National Cause of Death Register).

\section{Immunohistochemistry}

Formalin fixed and paraffin embedded samples were sectioned and used for immunohistochemistry. Deparaffinised sections were treated with $0.3 \% \mathrm{H}_{2} \mathrm{O}_{2}$ for 30 minutes, microwave treated in $0.01 \mathrm{M}$ citrate buffer $\mathrm{pH} 6.0$ for $2 \times 10$ minutes, washed for five minutes in phosphate buffered saline (PBS), and blocked for 20 minutes in $2 \%$ bovine serum albumin (BSA) in PBS. A polyclonal antihuman PDGFR $\alpha$ antiserum (C-20, Santa Cruz Biotechnology, California, USA) diluted $1: 200$ in PBS with $0.1 \%$ BSA was used as a primary antibody. Incubation at $4^{\circ} \mathrm{C}$ overnight was followed by incubation with a biotinylated swine antirabbit antibody (E0353, Dako, Glostrup, Denmark) for 30 minutes at room temperature. The immune reactions were visualised with an avidinbiotin complex (Vectastain, Vector Laboratories, Burlingame, California, USA) followed by 3,3'-diaminobenzoidine tetrahydrochloride (DAB; Sigma, St Louis, Missouri, USA) with Ni enhancement. ${ }^{18}$ Sections incubated without a primary antibody were used as a negative control. All sections were counterstained in Mayer's haematoxylin-eosin (fig 1).

To check the specificity of the immunostaining, we used cultured porcine aortic endothelial cells (Paec) transfected with human PDGFR $\alpha$ (Zar 15) $)^{19}$ and PDGFR $\alpha$ cDNA (Znr 5), ${ }^{20}$ respectively. Non-transfected Paec cells served as a negative control. These cells were pelleted, fixed in formalin, dehydrated, and embedded in paraffin. We also performed blocking experiments, where the C-20 antibodies were preincubated at $4^{\circ} \mathrm{C}$ overnight with $0.1 \mathrm{mM}$ of the corresponding peptide (TIE; amino acids 1066-1084 of human PDGFR $\alpha$ ), ${ }^{21}$ or with the same concentration of an unrelated peptide (TGF $\beta_{1}$ (sc-146P), Santa Cruz Biotechnology), or without addition of peptides. All incubations were in PBS with $0.1 \%$ BSA.

\section{Immunohistochemical analysis}

The degree of staining was estimated by counting positively stained cells to a total of 150-200 cells for each sample. As all samples contained some positively stained cells, it was not possible to set a cut off for negative staining. The degree of staining was therefore documented continuously as a percentage. The counts were performed independently by two of us (JA and AS), who had no access to the survival data of the patients. In 13 samples a heterogeneous picture within the same tumour was seen. In these cases the interobserver variability exceeded $10 \%$, and thus twice the number of counted areas was analysed to obtain representative estimations of the number of positive cells in the tumours.

\section{Statistical analyses}

Cox's proportional hazard model was used to calculate the impact of the variables on prognosis in univariate and multivariate survival analyses. In the univariate analysis, we estimated the statistical significance of the clinical, histological, and radiological variables, as well as of PDGFR $\alpha$ expression. The three most important variables in the univariate analysis were included simultaneously in the multivariate model. These variables were also entered as products in the model to test for interaction. As no interaction was demonstrated, the products of the variables were excluded from the model. In addition, histology was checked for confounding and interaction, but neither was present. The natural logarithm $(\ln )$ of the cumulative hazard plots was made to assess the assumption of the proportional hazard functions. All variables in the model fulfilled the assumption. To avoid an arbitrary dichotomy, the PDGFR $\alpha$ expression and preoperative duration of symptoms were entered as continuous variables. The Mann-Whitney U test was used to compare the PDGFR $\alpha$ expression between the categories of the other variables. The statistical calculations were performed in StatView 5.0 (SAS Institute Inc, Cary, North Carolina, USA).

\section{RESULTS}

\section{Patient and tumour characteristics}

The clinical data are presented in table 1 . The study population of 40 patients was followed until death or for a median of 8.5 
Table 1 Characteristics of the patients and their tumours

\begin{tabular}{|c|c|c|c|c|c|c|}
\hline Patient No & Age/sex & Symptoms/ KPS & Histology I & $\begin{array}{l}\text { PDGFR } \alpha \text { positive } \\
\text { cells I (\%) }\end{array}$ & Histology II & $\begin{array}{l}\text { PDGFR } \alpha \text { positive cells } \\
\text { II (\%) }\end{array}$ \\
\hline 1 & $33 / F$ & $\mathrm{Ep}, \mathrm{C} / 90$ & A-2 & 40 & - & - \\
\hline 2 & $29 / F$ & $\mathrm{Ep}, \mathrm{OS} / 90$ & A-2 & 33 & A-2 & 40 \\
\hline 3 & $34 / \mathrm{F}$ & $\mathrm{Ep}, \mathrm{H} / 90$ & A-2 & 29 & $\mathrm{OA}-2$ & 60 \\
\hline 4 & $31 / M$ & $\mathrm{Ep} / 90$ & $\mathrm{~A}-2$ & 50 & OA-3 & 27 \\
\hline 5 & $24 / M$ & OS $/ 90$ & A-2 & 35 & - & - \\
\hline 6 & $59 / \mathrm{M}$ & $\mathrm{Ep} / 90$ & A-2 & 54 & - & - \\
\hline 7 & $35 / M$ & $\mathrm{Ep} / 90$ & A-2 & 62 & A-2 & 33 \\
\hline 8 & $63 / M$ & $\mathrm{Ep}, \mathrm{C} / 80$ & A-2 & 53 & - & - \\
\hline 9 & $30 / M$ & $\mathrm{Ep} / 90$ & A-2 & 31 & - & - \\
\hline 10 & $62 / M$ & $\mathrm{P} / 40$ & A-2 & 45 & - & - \\
\hline 11 & $57 / M$ & $\mathrm{Ep}, \mathrm{H} / 90$ & A-2 & 25 & - & - \\
\hline 12 & $79 / F$ & Ep,P/70 & A-2 & 5 & - & - \\
\hline 13 & $49 / \mathrm{M}$ & $\mathrm{Ep}, \mathrm{C} / 90$ & A-2 & 29 & - & - \\
\hline 14 & $36 / M$ & $\mathrm{Ep} / 90$ & A-2 & 40 & - & - \\
\hline 15 & $33 / M$ & $\mathrm{Ep} / 90$ & A-2 & 33 & - & - \\
\hline 16 & $69 / \mathrm{M}$ & $\mathrm{Ep}, \mathrm{OS} / 90$ & $\mathrm{~A}-2$ & 10 & - & - \\
\hline 17 & $48 / M$ & $\mathrm{Ep}, \mathrm{P} / 70$ & $\mathrm{OA}-2$ & 50 & - & - \\
\hline 18 & $41 / M$ & $\mathrm{Ep}, \mathrm{H}, \mathrm{C} / 90$ & OA-2 & 51 & - & - \\
\hline 19 & $40 / M$ & $\mathrm{Ep}, \mathrm{C} / 80$ & A-2 & 38 & - & - \\
\hline 20 & $39 / F$ & $\mathrm{Ep} / 90$ & A-2 & 43 & - & - \\
\hline 21 & $46 / M$ & $\mathrm{Ep} / 90$ & A-2 & 34 & $\mathrm{~A}-3$ & 0 \\
\hline 22 & $39 / M$ & $\mathrm{Ep} / 90$ & $\mathrm{OA}-2$ & 46 & $\mathrm{~A}-3$ & 20 \\
\hline 23 & $29 / F$ & $\mathrm{Ep}, \mathrm{H} / 90$ & $\mathrm{~A}-2$ & 40 & A-3 & 19 \\
\hline 24 & $40 / M$ & $C, O S / 60$ & A-2 & 61 & - & - \\
\hline 25 & $67 / F$ & $\mathrm{Ep}, \mathrm{C} / 90$ & OA-2 & 47 & - & - \\
\hline 26 & $35 / M$ & $\mathrm{Ep} / 90$ & A-2 & 31 & - & - \\
\hline 27 & $48 / M$ & $\mathrm{Ep} / 90$ & A-2 & 70 & - & - \\
\hline 28 & $31 / M$ & $\mathrm{Ep}, \mathrm{H} / 90$ & A-2 & 34 & - & - \\
\hline 29 & $20 / M$ & $\mathrm{H}, \mathrm{OS} / 90$ & A-2 & 37 & - & - \\
\hline 30 & $30 / M$ & $\mathrm{Ep} / 90$ & A-2 & 47 & - & - \\
\hline 31 & $51 / \mathrm{F}$ & $\mathrm{Ep}, \mathrm{H} / 90$ & $\mathrm{~A}-2$ & 59 & - & - \\
\hline 32 & $36 / M$ & $\mathrm{Ep} / 90$ & $\mathrm{~A}-2$ & 29 & - & - \\
\hline 33 & $47 / M$ & $\mathrm{Ep} / 90$ & $\mathrm{OA}-2$ & 65 & - & - \\
\hline 34 & $36 / F$ & $\mathrm{Ep}, \mathrm{H} / 90$ & A-2 & 47 & - & - \\
\hline 35 & $40 / M$ & $\mathrm{Ep}, \mathrm{C} / 80$ & A-2 & 55 & - & - \\
\hline 36 & $47 / M$ & $\mathrm{Ep}, \mathrm{H} / 90$ & OA-2 & 29 & - & - \\
\hline 37 & $53 / \mathrm{M}$ & $\mathrm{H}, \mathrm{C}, \mathrm{OS} / 70$ & $\mathrm{~A}-2$ & 34 & - & - \\
\hline 38 & $41 / M$ & $\mathrm{Ep} / 90$ & $\mathrm{~A}-2$ & 48 & - & - \\
\hline 39 & $38 / M$ & $\mathrm{Ep} / 90$ & $\mathrm{~A}-2$ & 53 & - & - \\
\hline 40 & $52 / M$ & $\mathrm{Ep}, \mathrm{C} / 90$ & $\mathrm{OA}-2$ & 56 & - & - \\
\hline
\end{tabular}

A-2/3, astrocyłoma, WHO grade 2/3; C, cognitive dysfunction; Ep, epileptic seizure or epilepsy; $F$, female; $H$, headache; KPS, Karnofsky performance status; $M$, male; OA-2/3, oligoastrocytoma, WHO grade 2/3; OS, other symptoms; P, paresis; I, first operation/biopsy; II, second operation/biopsy.

years (range 6.6 to 12.5 ). Thirty three patients had grade 2 astrocytomas and seven had grade 2 oligoastrocytomas according to the WHO criteria. Only three astrocytomas had an oligodendrocyte involvement of $20-40 \%$. Median age at the time of histological diagnosis was 40 years (range 19 to 78 ). The most common presenting symptom was seizures $(87.5 \%)$, and occurred as the only presenting symptom in 16 patients $(40 \%)$. Median time from symptom onset to diagnosis was 21 weeks. A frontal location was the most common (65\%), followed by temporal $(42.5 \%)$ and parietal $(20 \%)$. Four tumours $(10 \%)$ had a central extension. Tumours were multilobed in 14 patients (35\%), usually frontotemporal. In 21 patients the tumour was excised: subtotal resection in 14 and macroscopic total resection in seven. Ultrasound guided or stereotactic biopsy was performed in the remaining cases. Most of the patients ( $85 \%$ ) received radiotherapy postoperatively in 1.8-2.0 grey (Gy) fractions to a total dose of 43.5-60.0 Gy (median dose 50.2 Gy).

\section{PDGFR $\alpha$ expression}

Analysis of the tumour sections showed that all tumour samples were positively stained but there was a relatively large variation in the percentage of positively stained cells between samples from different tumours (table 1). The median for the fraction of PDGFR $\alpha$ expressing cells was $41.5 \%$ (range $5-70 \%)$. In the comparison of the PDGFR $\alpha$ expression between the categories of the other variables, no statistically significant difference was noticed. For example, there was no difference in PDGFR $\alpha$ expression between patients aged $\leqslant 45$ (median $40 \%$ ) years and patients aged $>45$ years (median $46 \%)(p=0.83)$. However, there was a trend towards a higher fraction of PDGFR $\alpha$ expressing cells in oligoastrocytomas compared with astrocytomas $(p=0.13)$. When adding the values for the three grade 2 tumours at reoperation, there was

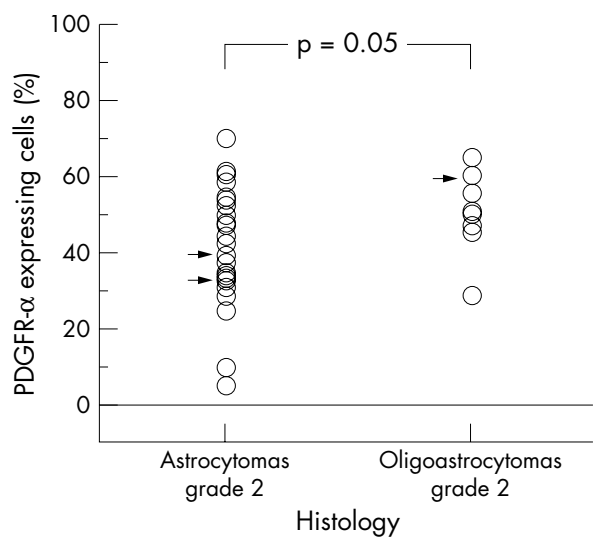

Figure 2 Comparison of expression of platelet derived growth factor $\alpha$ receptor between grade 2 astrocytomas and grade 2 oligoastrocytomas. Arrows indicate three grade 2 tumours at reoperation. 
Table 2 Prognostic factors using Cox's proportional hazards model

\begin{tabular}{|c|c|c|c|c|c|c|}
\hline \multirow[b]{2}{*}{ Parameter } & \multicolumn{3}{|c|}{ Univariate analysis } & \multicolumn{3}{|c|}{ Multivariate analysis } \\
\hline & $\begin{array}{l}\text { Hazard } \\
\text { ratio }\end{array}$ & $95 \% \mathrm{Cl}$ & $\mathrm{p}$ Value & $\begin{array}{l}\text { Hazard } \\
\text { ratio }\end{array}$ & $95 \% \mathrm{Cl}$ & $\mathrm{p}$ Value \\
\hline KPS $(\geqslant 90 v \leqslant 80)$ & 0.40 & 0.18 to 0.92 & 0.03 & 0.33 & 0.14 to 0.75 & 0.009 \\
\hline PDGFR $\alpha$ & 0.96 & 0.94 to 0.99 & 0.04 & 0.96 & 0.93 to 0.99 & 0.02 \\
\hline Age ( $>45$ years $v \leqslant 45$ years) & 1.49 & 0.72 to 3.08 & 0.29 & 1.60 & 0.76 to 3.39 & 0.22 \\
\hline Preop duration of symptoms & 1.00 & 0.99 to 1.01 & 0.38 & - & - & - \\
\hline Side (left $v$ right) & 1.35 & 0.67 to 2.70 & 0.40 & - & - & - \\
\hline Contrast enhancement & 1.32 & 0.66 to 2.63 & 0.44 & - & - & - \\
\hline Histology $(A \vee O A)$ & 1.39 & 0.53 to 3.62 & 0.51 & - & - & - \\
\hline Sex (male $v$ female) & 1.33 & 0.57 to 3.11 & 0.51 & - & - & - \\
\hline Epilepsy only & 0.91 & 0.45 to 1.85 & 0.79 & - & - & - \\
\hline Total resection & 0.84 & 0.36 to 1.97 & 0.69 & - & - & - \\
\hline Radiotherapy (yes v no) & 1.98 & 0.60 to 2.63 & 0.23 & - & - & - \\
\hline
\end{tabular}

A, astrocytoma; Cl, confidence interval; KPS, Karnofsky performance status; OA, oligoastrocytoma; PDGFR, platelet derived growth factor receptor.

a higher fraction of PDGFR $\alpha$ expressing cells in grade 2 oligoastrocytomas (median 50\%) than in grade 2 astrocytomas (median 40\%) ( $\mathrm{p}=0.05$ ) (fig 2 ). The PDGFR $\alpha$ expression did not differ among fibrillary, gemistocytic, and protoplasmic astrocytomas (data not shown).

\section{Prognostic factors}

The survival analyses are presented in table 2. At the end of the study 33 patients $(82.5 \%)$ had died. For all deceased patients, the tumour was noted as the direct or underlying cause of death in the National Cause of Death Register.

The median overall survival time was 4.2 years and the overall five year survival was 38\% (Kaplan-Meier estimate). Of the variables included in the univariate Cox analysis, the Karnofsky performance status and PDGFR $\alpha$ expression were both statistically significant $(p=0.03$ and $p=0.04$, respectively). The median survival time for patients with Karnofsky performance status $\geqslant 90$ was 4.4 years compared with 1.1 years for patients with Karnofsky performance status $\leqslant 80$ (Kaplan-Meier estimate). Karnofsky performance status and PDGFR $\alpha$ expression were also statistically significant in the multivariate analysis $(p=0.009$ and $p=0.02$, respectively; Wald $p=0.01$, likelihood ratio $p=0.01$ ). Both variables were considered to be independent prognostic factors. Age was also included in the multivariate survival model but was not significant on its own $(p=0.22)$. There was no confounding by age, but the variable was kept in the model as there was no significant precision loss by its inclusion and because it has been one of the most important survival factors in other studies. The type of treatment given had no positive effect on the patients' survival.

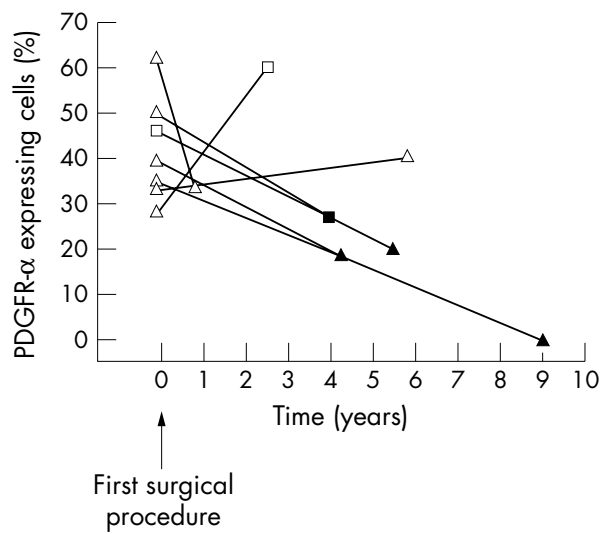

Figure 3 Changes in the expression of platelet derived growth factor $\alpha$ receptor in the seven patients with tumour samples obtained on two different occasions. Triangles, astrocytomas; squares, oligoastrocytomas; empty symbols, grade 2; filled symbols, grade 3.

\section{Malignant progression}

Malignant progression had occurred in four of the seven patients who had repeat operations (table 1; fig 3). In all four tumours malignant progression was associated with a significant decrease in the number of PDGFR $\alpha$ expressing cells (from a median of $43 \%$ to a median of $19.5 \%$ ). In two of these patients there was also an additional change in histology: in one case from astrocytoma to oligoastrocytoma and in the other the converse. The only patient with a significant increase in PDGFR $\alpha$ expression at reoperation had a histological shift from astrocytoma to oligoastrocytoma without progression to a more malignant grade.

\section{DISCUSSION}

In this study we showed that patients with grade 2 astrocytomas or oligoastrocytomas are at an advantage if their tumours contain a relatively high fraction of PDGFR $\alpha$ expressing cells on immunohistochemistry. The role of PDGF and PDGF receptors in the development of human gliomas is well established, but all published reports so far have explored the relation with histopathological diagnosis and not with survival.

Experimental evidence has accumulated over the years that PDGF and its receptors promote growth by both paracrine and autocrine loops (reviewed by Westermark et al, 1995 ${ }^{15}$ ). PDGFR $\alpha$ mRNA has been found in all grades of glial tumours, and overexpression of the PDGFR $\alpha$ is considered to be an early event in tumour development. ${ }^{22}$ However, previous reports have shown the greatest PDGFR $\alpha$ mRNA expression in glioblastomas, the most malignant form of glial tumours. ${ }^{14}$ Amplification of the PDGFR $\alpha$ gene with correspondingly high levels of protein expression has been shown in a few cases of glioblastoma. ${ }^{23}$ Thus, although overexpression of PDGFR $\alpha$ is an early event, further upregulation seems to occur during tumour progression in at least some cases.

The overexpression of the PDGF $\mathrm{A}$ and $\mathrm{B}$ chains is considered to be a later phenomenon in the malignant development from low grade to anaplastic glioma. The expression of PDGF A and B chains has been found to be absent or low in tumour samples from grade 2 gliomas, whereas the level of expression in anaplastic gliomas and glioblastomas has been high. ${ }^{22}$ Consequently, the basis for paracrine and autocrine loops exists in gliomas of grades 3-4 but not necessarily in the low grade gliomas. High concentrations of PDGF have also been measured in cyst fluid from grade 3-4 astrocytomas. In most cases, the concentrations have been considerably higher than the levels required for maximum PDGF effect on cells in vitro. $^{24}$

As well as showing that PDGFR $\alpha$ expression had prognostic significance, we found a slightly higher fraction of PDGFR $\alpha$ expressing cells in grade 2 oligoastrocytomas than in grade 2 astrocytomas (fig 2). In the light of these findings, it is possible that the expression of PDGFR $\alpha$ is a marker for the 
oligodendrocyte component in the tumours. Expression of PDGFR $\alpha$ has been demonstrated on oligodendrocyte precursor cells $(\mathrm{O}-2 \mathrm{~A}),{ }^{25}{ }^{26}$ and on oligodendroglioma cells. ${ }^{27}$ In a recent study of a larger population of gliomas, amplification of the PDGFR $\alpha$ gene was only observed in highly anaplastic tumours with oligodendroglial differentiation, and not in astrocytic tumours. ${ }^{28}$ Thus PDGFR $\alpha$ expression is an important feature of tumours of oligodendroglial lineage. As patients with grade 2 oligodendrogliomas have a more favourable prognosis than those with grade 2 astrocytomas, ${ }^{1}$ the oligodendrocyte component of the tumour is expected to correlate with survival. On the other hand, this is probably not the only explanation for the findings, as the receptor expression in the oligoastrocytomas remains in the same interval as the astrocytomas with high receptor expression (fig 2).

Another interesting hypothesis could be that the tumours stem from two different precursor cells-that is, the astrocytic tumour cells have a different origin. It has been suggested that patients with tumours of purely cortical localisation and with chronic epilepsy as the only symptom represent a distinct pathological entity. ${ }^{29}$ The outcome for such patients is significantly better than for patients with tumours localised to the white matter and with more complex symptoms. It is proposed that low grade gliomas with chronic epilepsy resemble the phenotype of the type 1 astrocyte lineage (1A), whereas white matter tumours resemble the type 2 lineage $(\mathrm{O}-2 \mathrm{~A}) .{ }^{29}{ }^{30}$ In our sample, 14 of the 33 patients with astrocytoma had epilepsy as the only symptom. These tumours showed a generally higher proportion of positive cells stained with the anti-PDGFR $\alpha$ antiserum than the 19 tumours in patients with different or more complex symptoms $(45 \% \mathrm{v}$ $37 \%, p=0.27$, NS). Because of technical difficulties we were not able to re-examine the CT and MRI scans to see whether the white matter was involved in the spread of the tumour in each individual patient.

A third possibility is that tumours with a low PDGFR $\alpha$ expression have a higher invasive capacity than tumours with high expression of the receptor. Chekenya et al have shown that human gliomas express NG2, a transmembrane proteoglycane that identifies O-2A progenitor cells in the adult human brain. ${ }^{31}$ The expression of NG2 on the tumour cells in their study was colocalised with the expression of PDGFR $\alpha$. Low expression of NG2 was associated with a greater tendency toward invasion, rather than proliferation, of the glioma cells in vitro. In relation to our study, this would suggest that the tumours with low expression of PDGFR $\alpha$ were more effective at infiltrating the surrounding brain tissue, which would worsen the prognosis.

Our results show a reduction in receptor protein expression in all tumours with verified malignant progression (fig 3). These might be secondary effects owing to the presence of high, or abnormally high, concentrations of ligand in anaplastic gliomas and subsequent receptor downregulation. If this were true, it does not necessarily mean a lower degree of receptor activation in the anaplastic cases.

\section{Limitations}

Retrospective review is not optimal for collecting clinical data. In some instances there may be selection of patients with respect to age, performance status, or the patient's preferences. In our experience, however, most patients with a suspected brain tumour are referred to the department of neurosurgery for further diagnostic investigation and treatment. Although the study population is rather small, we have no reason to believe that it is not representative of the population of astrocytomas and oligoastrocytomas of WHO grade 2.

Our results were obtained by a semiquantitative technique based on immunohistochemical analysis which also requires some caution in the interpretation of the data. However, the different experiments including controls for specificity and sensitivity showed a high consistency. On these grounds the results can be regarded as reliable. Further studies using larger patient populations and other laboratory techniques will be needed to confirm the prognostic significance of PDGFR $\alpha$ in grade 2 astrocytomas and oligoastrocytomas, and the potential use of the receptor as a prognostic marker in the clinic setting.

\section{Conclusions}

In this retrospective study we showed that high PDGFR $\alpha$ expression is a favourable prognostic factor patients with grade 2 astrocytomas and grade 2 oligoastrocytomas. Our findings indicate that there is a variable expression of the receptor which is potentially useful in assessing likely survival.

\section{ACKNOWLEDGEMENTS}

This work was supported by grants from Erik, Karin and Gösta Selander's Foundation, the Lions Cancer Foundation, the Swedish Cancer foundation, the Swedish Childhood Cancer Foundation, and Mary Béve's Foundation.

\section{Authors' affiliations}

D Ribom, A Smits, Department of Neuroscience, Neurology, University Hospital, Uppsala, Sweden

J Andræ, M Frielingsdorf, $\mathbf{M}$ Hartman, $\mathbf{M}$ Nistér, Department of Genetics and Pathology, Rudbeck Laboratory, University Hospital, Uppsala

\section{REFERENCES}

1 Bampoe JO, Bauman G, Cairncross JG. Adult low-grade gliomas: natural history, prognostic factors, and timing of treatment. In: Rock JP Rosenblum ML, Shaw EG, Cairncross JG, eds. The practical management of low-grade primary brain tumors. Philadelphia: Lippincott Williams and Wilkins, 1999: 135-48.

2 Lote K, Egeland T, Hager B, et al. Survival, prognostic factors, and therapeutic efficacy in low-grade glioma: a retrospective study in 379 patients. J Clin Oncol 1997; 15:3129-40.

3 Karim AB, Maat B, Hatlevoll R, et al. Randomized trial on dose-response in radiation therapy of low-grade cerebral glioma: European Organization for Research and Treatment of Cancer (EORTC) Study 22844. Int J Radiat Oncol Biol Phys 1996;36:549-56.

4 Karim AB, Afra D, Cornu P, et al. Randomized trial on the efficacy of radiotherapy for cerebral low-grade glioma in the adult: European Organization for Research and Treatment of Cancer Study 22845 with the Medical Research Council study BRO4: an interim analysis. Int J Radiat Oncol Biol Phys 2002;52:316-24.

5 Kiebert GM, Curran D, Aaronson NK, et al. Quality of life after radiation therapy of cerebral low-grade gliomas of the adult: results of a randomised phase III trial on dose response (EORTC trial 22844). EORTC Radiotherapy Co-operative Group. Eur J Cancer 1998;34:1902-9.

6 Shaw E, Arusell R, Scheithauer B. A prospective randomized trial of low versus high-dose radiation therapy in adults with supratentorial low-grade glioma: initial report of a NCCTG-RTOG-ECOG-study [abstract]. Proc Am Soc Clin Oncol 1998:17:401.

7 Schroder R, Bien K, Kott R, et al. The relationship between Ki-67 labeling and mitotic index in gliomas and meningiomas: demonstration of the variability of the intermitotic cycle time. Acta Neuropathol (Berl) 1991;82:389-94.

8 Abdulrauf SI, Edvardsen K, Ho KL, et al. Vascular endothelial growth factor expression and vascular density as prognostic markers of survival in patients with low-grade astrocytoma. J Neurosurg 1998;88:513-20.

9 Heldin $\mathbf{C H}$, Westermark B. Platelet-derived growth factor: mechanism of action and possible in vivo function. Cell Regul 1990;1:555-66.

10 Bergsten E, Uutela M, Li X, et al. PDGF-D is a specific, protease-activated ligand for the PDGF beta-receptor. Nat Cell Biol $2001 ; 3: 512-16$.

11 LaRochelle WJ, Jeffers M, McDonald WF, et al. PDGF-D, a new protease-activated growth factor. Nat Cell Biol 2001;3:517-21.

12 Li X, Ponten A, Aase K, et al. PDGF-C is a new protease-activated ligand for the PDGF alpha-receptor [see comments]. Nat Cell Biol 2000;2:302-9.

13 Gilbertson DG, Duff ME, West JW, et al. Platelet-derived growth factor C (PDGF-C) a novel growth factor that binds to PDGF $\{$ alpha $\}$ and $\{$ beta receptor. J Biol Chem 2001:10:10.

14 Hermanson M, Funa K, Koopmann J, et al. Association of loss of heterozygosity on chromosome $17 \mathrm{p}$ with high platelet-derived growth factor alpha receptor expression in human malignant gliomas. Cancer Res 1996:56:164-71.

15 Westermark B, Heldin CH, Nister M. Platelet-derived growth factor in human glioma. Glia 1995;15:257-63. 
16 Kleihues P, Burger PC, Scheithaver BW. The new WHO classification of brain tumours. Brain Pathol 1993;3:255-68.

17 Karnofsky DA, Abelmann WH, Craver LF. The use of nitrogen mustards in the palliative treatment of carcinoma. With particular reference to bronchogenic carcinoma. Cancer 1948:1:634-56.

18 Shu SY, Ju G, Fan LZ. The glucose oxidase-DAB-nickel method in peroxidase histochemistry of the nervous system. Neurosci Lett 1988;85:169-71.

19 Eriksson A, Siegbahn A, Westermark B, et al. PDGF alpha- and beta-receptors activate unique and common signal transduction pathways. Embo J 1992;1 1:543-50.

20 Westermark B, Siegbahn A, Heldin $\mathrm{CH}$, et al. B-type receptor for platelet-derived growth factor mediates a chemotactic response by means of ligand-induced activation of the receptor protein-tyrosine kinase. Proc Natl Acad Sci USA 1990;87:128-32.

21 Claesson-Welsh L, Eriksson A, Westermark B, et al. cDNA cloning and expression of the human A-type platelet-derived growth factor (PDGF) receptor establishes structural similarity to the B-type PDGF receptor. Proc Natl Acad Sci USA 1989;86:4917-21.

22 Hermanson $M$, Funa K, Hartman M, et al. Platelet-derived growth factor and its receptors in human glioma tissue: expression of messenger RNA and protein suggests the presence of autocrine and paracrine loops. Cancer Res 1992;52:3213-19.

23 Fleming TP, Saxena A, Clark WC, et al. Amplification and/or overexpression of platelet-derived growth factor receptors and epidermal growth factor receptor in human glial tumors. Cancer Res 1992;52:4550-3.
24 Nister M, Enblad P, Backstrom G, et al. Platelet-derived growth factor (PDGF) in neoplastic and non-neoplastic cystic lesions of the central nervous system and in the cerebrospinal fluid. $\mathrm{Br} J$ Cancer 1994:69:952-6.

25 Calver AR, Hall AC, Yu WP, et al. Oligodendrocyte population dynamics and the role of PDGF in vivo. Neuron 1998;20:869-82.

26 Hart IK, Richardson WD, Heldin CH, et al. PDGF receptors on cells of the oligodendrocyte-type-2 astrocyte (O-2A) cell lineage. Development 1989; 105:595-603.

27 Di Rocco F, Carroll RS, Zhang J, et al. Platelet-derived growth factor and its receptor expression in human oligodendrogliomas. Neurosurgery 1998;42:341-6.

28 Smith JS, Wang XY, Qian J, et al. Amplification of the platelet-derived growth factor receptor-A (PDGFRA) gene occurs in oligodendrogliomas with grade IV anaplastic features. J Neuropathol Exp Neurol 2000:59:495-503.

29 Bartolomei JC, Christopher S, Vives K, et al. Low-grade gliomas of chronic epilepsy: a distinct clinical and pathological entity. J Neurooncol 1997;34:79-84.

30 Piepmeier JM, Fried I, Makuch R. Low-grade astrocyłomas may arise from different astrocyte lineages. Neurosurgery 1993;33:627-32

31 Chekenya M, Rooprai HK, Davies D, et al. The NG2 chondroitin sulfate proteoglycan: role in malignant progression of human brain tumours. Int $\mathrm{J}$ Dev Neurosci 1999;17:421-35

\section{NEUROLOGICAL STAMP}

\section{Luis Morquio (1867-1935)}

uis Morquio qualified in medicine from the University of Montevideo in 1892. After the completion of his medical training in Paris Lhe studied at the Pasteur Institute. He specialised in paediatrics. In 1894 he returned to Uruguay, where he became the director of a newly established paediatric clinic and professor of paediatrics in Montevideo. Eponymically he is remembered for Morquio's syndrome, otherwise known as mucopolysaccharidosis type IV. This is one of the least common of the group of hereditary specific lysosomal enzyme deficiencies which cause pathological accumulation and urinary excretion of incompletely degraded mucopolysaccharides. In Morquio's syndrome cervical cord compression is the most severe complication, resulting from hypoplasia of the odontoid process with secondary atlantoaxial instability. This is one of the major causes of death in Morquio's syndrome. A stamp was issued in Morquio's honour in 1969, to commemorate the 100th year of his birth (Stanley Gibbons 1411, Scott C356).
LF Haas

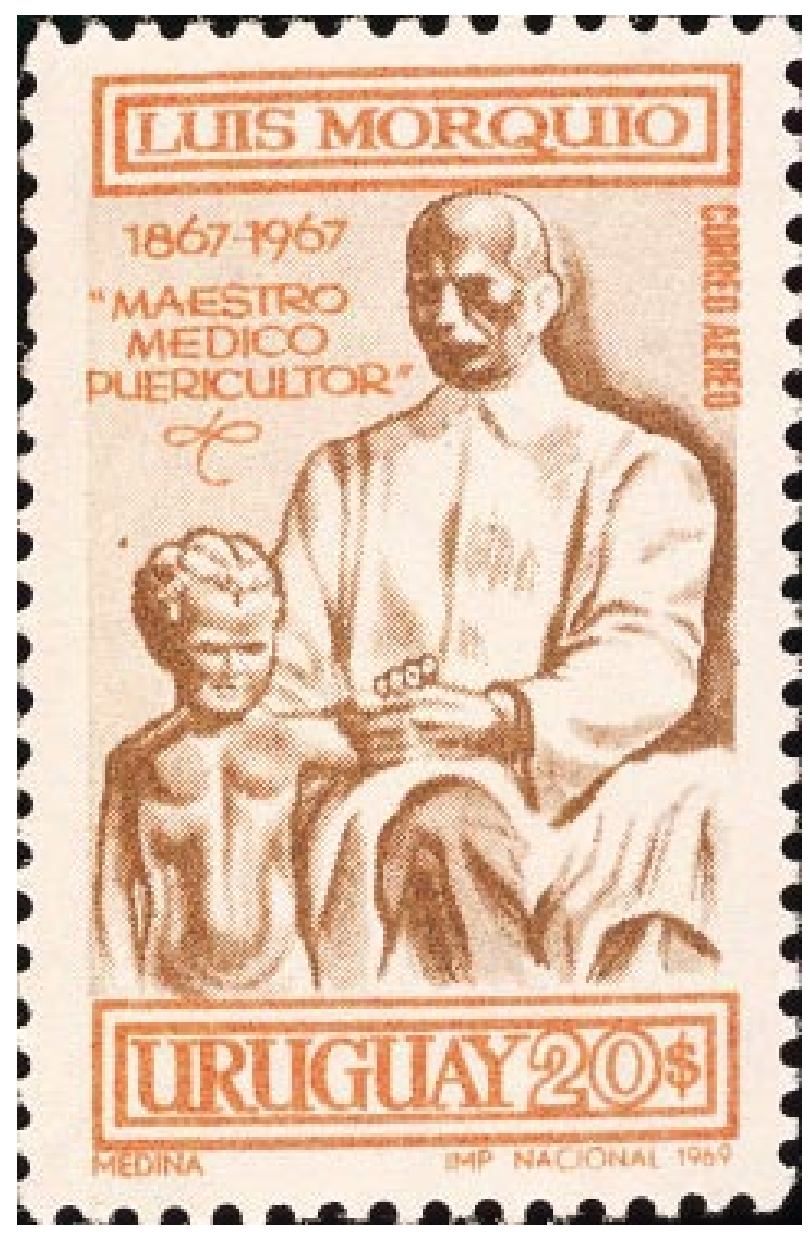

